(C) Н.В. Ахантьева, Н.Н. Абдуганиев

\title{
АДАПТАЦИЯ СТУДЕНТОВ-МИГРАНТОВ В НОВОЕ СОЦИОКУЛЬТУРНОЕ ПРОСТРАНСТВО В ВУЗАХ МОРДОВИИ
}

\begin{abstract}
На современном этапе развития государства происходит интенсификация миграчионных прочессов, в которых особое место занимает учебная миграция. Ежегодно большое число молодых людей пересекают нашу гранииу с иелью получить образование, и в дальнейшем многие из них планируют остаться в РФ на постоянное место жительства. Значительная часть студентов-мигрантов испьтывьват на первых порах неудобства из-за языкового барьера, новизнь сочиокультурного пространства, незнакомых климатических условий. Перед вузами Российской Федерации, в частности перед вузами Республики Мордовия стоит первостепенная задача создать необходимые условия для максимально скорой адаптации иностранных студентов в незнакомую для них среду. Для обеспечения научного подхода к проблеме многое могут сделать ученье, работающие в этом направлении, что находит отражение в научных исследованиях. B статье предпринята попьтка анализа практической деятельности двух крупнейших вузов республики в обозначенной сфере. Данные учебные учреждения ведут эту работу уже не один десяток лет, с каждым годом ее всё более совериенствуя в соответствии с реалиями современного мира.
\end{abstract}

Ключевые слова: сочиокультурное пространство, студенческая миграчия, студенты-мигранты, иностранные студенты, этнокультурная адаптация

Ссылка при цитировании: Ахантьева Н.В., Абдуганиев Н.Н. Адаптация студентов-мигрантов в новое социокультурное пространство в ВУЗах Мордовии // Вестник антропологии, 2021. № 2. С. 241-247.

В рамках данной статьи будет рассмотрен такой вид миграции, как учебная, так как именно она приобретает в последнее время все более масштабный характер. Иностранные студенты приезжают в Россию для получения образования, которое возможно по программам бакалавриата, специалитета, магистратуры и аспирантуры. Кроме того, в РФ студенты-мигранты могут получить среднее специальное образование. Последние, как правило, пересекают границу вместе с родителями, которые прибывают в нашу страну по разным причинам. Адаптационные процессы у студентов имеют определенные трудности, начиная от языкового барьера и заканчивая неподготовленностью принимающей стороны. Решением данной проблемы в теоретическом плане занимаются ученые (социологи, психологи, этнографы), а

Ахантьева Наталья Владимировна - преподаватель факультета довузовской подготовки и среднего профессионального образования, ФГБОУ ВО «МГУ им. Н. П. Огарёва» (430005 Саранск, ул. Большевистская, 68). Эл. почта: akhanteva.natasha@mail.ru

Абдуганиев Назиржон Насибжонович - заместитель председателя Совета, Ассамблея народов России (125009 Москва, Малый Гнездниковский пер., д. 12, стр. 4). Эл. почта: nazir1970@yandex.ru 
впрактическом - общественные организации и сами учебные учреждения, в которых иностранные студенты получают образование.

Разработка методических подходов к процессу адаптации иностранных студентов с каждым годом становится все более актуальной, что не могло не найти отражения в науке. Вопросы адаптации становятся предметом исследования в многочисленных публикациях, в кандидатских и докторских работах, посвященных деятельности учреждений социокультурной сферы в решении рассматриваемого вопроса. Особое внимание уделяется изучению регионального аспекта учебной миграции (Воробьева 2015; Зангиева, Сулейманова 2016; Гез, Старикова 2018, Серафимович 2018, Никонова 2020 и др.). В данной статье речь пойдет, главным образом о практической работе республиканских учебных учреждений, направленной на адаптацию иностранных студентов к новой для них среде.

Попадая в незнакомую для себя обстановку студенты-мигранты должны адаптироваться к ней с разных сторон, от того насколько будет успешным данный процесс, зависит дальнейшее пребывание иностранных студентов в нашей стране и качество получения образования, а, следовательно, качество подготовки специалиста в соответствии с современными требованиями рынка труда. Вузы страны, в частности Республики Мордовия, проводят огромную работу по интернациональному воспитанию молодежи. Эта деятельность ведется уже многие годы, именно с того момента, как республиканские вузы стали занимать прочное место на международном рынке образовательных услуг, она с каждым годом совершенствуется в соответствии с реалиями современного мира.

Иностранные студенты приезжают учиться в Мордовию не первый десяток лет. Их привлекает в первую очередь качество образования, которое имеет фундаментальный характер и что немало важно дружелюбие жителей. В Мордовии ведущими вузами являются ФГБОУ ВО «МГУ им. Н.П. Огарёва» и МГПУ им. М. Е. Евсевьева. В $2019^{1}$ году в мордовских вузах получали высшее образование 2253 иностранных студента. Из них 1800 человек из 57 стран - в МГУ им. Огарева, 442 из 8 стран МГПИ им. Евсевьева. В Саранском кооперативном институте обучалось 12 студентов из 6 стран. Востребованными становятся образовательные услуги и учреждений среднего профессионального образования. Так 16 иностранных студентов из 7 стран ближнего и дальнего зарубежья получали знания в Ичалковском педагогическом колледже, Саранском автомеханическом техникуме, Саранском государственном промышленно-экономическом колледже, Саранском музыкальном училище имени Л.П. Кирюкова, медицинском колледже.

Анализ статистических данных, характеризующих распределение мигрантов (с 14 лет) по возрастным группам и обстоятельствам, вызвавшим необходимость смены места жительства в 2019 году, свидетельствует, что из числа прибывших в республику 20553 человек были в возрасте 14-15 лет - 382 человека, 16-17 лет - 934 человека, 18-19 лет - 2138 человека, 20-24 лет - 4464 человека, 25-29 лет - 2769 человека. Оставшиеся мигранты были в возрасте от 30 лет и старше (Статистический сборник № 903).

В рамках исследования учебной миграции и адаптационных процессов иностранных студентов важно сопоставить эти данные с количеством мигрантов в возрасте

${ }^{1}$ В Территориальном органе Федеральной службы государственной статистики по РМ на момент подготовки статьи более актуальные данные отсутствуют. 
от 14 до 29 лет, которые пересекли границу Республики Мордовия с целью получения образования. Статистические данные Территориального органа Федеральной службы государственной статистики по Республике Мордовия свидетельствуют, что всего прибыло в республику 20553 человека, из них с целью получения образования - 4388 человек, что составило 21,4 \% из общего миграционного потока. По возрастам они распределяются следующим образом: 14-15 лет - 106 человек, 1617 лет - 620 человек, 18-19 лет - 1489 человек, 20-24 лет - 1841 человек, 25-29 лет 254 человека. Оставшиеся 78 человек, прибывшие в республику в связи с учебой, имеют возраст от 30 до 49 лет (Статистический сборник № 903).

ФГБОУ ВО «МГУ им. Н.П. Огарёва» занимает прочное место на рынке образовательных услуг. География студентов МГУ им. Н.П. Огарёва постоянно расширяется: в 2020 году, например, в Саранск приехали уроженцы Ганы, Сьерра-Леоне. В 2020/2021 учебном году в университете обучается 2130 иностранных граждан из более, чем 50 стран. Среди них: Абхазия, Австрия, Азербайджан, Алжир, Армения, Афганистан, Бангладеш, Боливия, Великобритания, Вьетнам, Гвинея, Грузия, Египет, Замбия, Зимбабве, Индия, Индонезия, Иордания, Ирак, Иран, Испания, Италия, Йемен, Казахстан, Камерун, Каморские острова, Кения, Китай, Колумбия, Конго, Кот-Д'Ивуар, Кыргызстан, Лаос, Мадагаскар, Марокко, Молдова, Пакистан, Палестина, Перу, Сирия, Сомали, Судан, Таджикистан, Того, Тунис, Туркменистан, Узбекистан, Украина, Чад, Эквадор, Эритрея, ЮАР, Южный Судан (Международные связи). Традиционно большое число абитуриентов приезжает из стран СНГ. В университете работает управление международных связей, сотрудники которого помогают иностранцам адаптироваться и влиться в учебный процесс (Там же).

«Из года в год желающих поступить к нам из-за рубежа становится все больше, отмечает ректор МГУ им. Н.П. Огарёва Сергей Вдовин. - В первую очередь это связано с тем, что мы активно внедряем преподавание на английском языке...». Если еще несколько лет назад 90\% иностранных студентов выбирали специальности медицинского института, сегодня соотношение изменилось, и уже $40 \%$ предпочитают другие институты и факультеты МГУ им. Н.П. Огарева. В качестве примера можно привести один из факультетов университета - филологический. Надежда Демкина, руководитель сектора по работе с иностранными студентами филологического факультета говорит: «У нас с каждым годом иностранцев становится всё больше и больше. Большинство из них приехали из Туркменистана. Но, кроме этого, есть ребята из Судана, Сербии, Румынии и даже Мадагаскара. По программе международного сотрудничества к нам прибыли итальянцы. В течение семестра они будут учить русский язык».

Махмуд Отман, студент филологического факультета МГУ им. Н.П. Огарёва рассказывает: «Я родился в Сирии, но вскоре мы с родителями переехали в Турцию. Стать журналистом - моя мечта. С детства я любил читать и сочинять рассказы. Поэтому выбор специальности сразу пал на журналистику. Оставалось только выбрать вуз. Как-то я приехал в Саранск в гости к другу и понял, что хочу учиться именно здесь. Привыкал тяжело: сильные морозы, другая еда. Сложность ещё состояла в том, что всё приходилось делать самому, а я никогда не жил один. Пришлось учиться готовить, стирать и убирать. Это очень трудно, тем более в чужой стране. Мне помогли курсы, которые я проходил в течение года перед поступлением. Мы учили русский язык, обществознание и историю России. Сейчас все занятия у нас прохо- 
дят на русском языке, поэтому иногда я не понимаю преподавателей. Русский очень сложный. Саранск мне нравится: чистый и спокойный город. Я ещё не знаю, где буду работать: в родной Турции или здесь, в Мордовии. Время покажет. Но я уверен в том, что журналистика мне нравится. Хотелось бы связать с ней свою жизнь».

В Мордовии функционирует Союз иностранных студентов МГУ им. Н.П. Огарёва. Общественная организация защищает интересы иностранных студентов, помогает им адаптироваться к новой среде и укрепляет «дружбу народов» в университете. Шакир Худояров - председатель Союза иностранных студентов МГУ им. Н.П. Огарёва говорит: «В университете я занимаюсь помощью иностранным студентам по самым разным проблемам. Мы помогаем в адаптации первокурсникам, решаем бытовые вопросы, консультируем по направлению миграционной политики. Серьёзных трудностей с иностранными студентами в Мордовии не возникало. Пожалуй, основной их проблемой является непривычный климат. Что же касается местных обычаев и традиций, студенты из других государств с удовольствием с ними знакомятся и принимают участие в праздниках. Культурный обмен идёт полным ходом, и это очень интересно обеим сторонам. Студенты-иностранцы отлично вписываются в общественную жизнь Саранска. Каких-то недопониманий не возникает. Они участвуют в общественных мероприятиях, много занимаются спортом: например, у нас в университете очень сильная футбольная команда студентов из Ирака, также ребята хорошо играют в баскетбол, ходят в бассейн. То есть живут обычной студенческой жизнью».

Работа в учебных заведениях по интернациональному воспитанию и совершенствованию адаптационных процессов ведется по нескольким направлениям: учебная деятельность, воспитательная работа, которая осуществляется путем привлечения иностранных студентов к участию в общественных мероприятиях различного уровня, преодоление языкового барьера, погружение иностранных студентов в знакомую для них культуру, путем проведения различных мероприятий, национальных праздников и т.д. Все эти направления тесно взаимосвязаны, так как именно это приводит к более скорейшему формированию речевой и социокультурной компетенций. Вузы республики ведут активную деятельность по решению задачи интеграции студентов-мигрантов в социально-культурную жизнь, а также формированию у них уважения к российским традициям и культуре. Большую роль в этом играет внеучебная работа, проводимая в соответствии с планом работы с иностранными студентами. В этом направлении используется большое количество уже наработанных методик, разработанных для проведения культурно-массовых мероприятий с этой категорией обучающихся.

В МГУ им. Н.П. Огарёва стало популярно участие творческих коллективов в ежегодном фестивале культур «Огарёвский колорит». Задача данного мероприятия - укрепить и расширить круг международных связей. Кроме того, это яркое событие имеет огромную воспитательную функцию, целью которой является неприятие таких проявлений среди обучающихся как экстремизм и национализм. В его рамках иностранные студенты представляют свои традиции и обычаи на выставке национальных культур, а также проводят мастер-классы по народному творчеству. Кроме того, фестиваль обычно проходит с праздничным концертом, где студенты - представители разных стран показывают творческие номера. Традиционные танцы и песни исполняют студенты Мордовского университета, приехавшие из разных уголков мира: из стран Африки и Латинской Америки, Китая, Индии, Пакистана, Туркменистана, Таджикистана, Узбекистана, Азербайджана, Афганистана, Армении, Сирии, Ирака и др. Выступление 
студентов с танцами, песнями народов мира стало традиционным на разных мероприятиях, связанных с добрососедскими отношениями населения Республики Мордовия. Например, одно из таких выступлений состоялось на фестивале «Этномир Республики Мордовия: перспективы межэтнического и межкультурного сотрудничества» (ВДНХ, пос. Ялга) с участием студентов из МГПИ им. М.Е. Евсевьева и МГУ им. Н.П. Огарёва. В их исполнении были показаны мастер-классы и выступления.

Объединяет ребят не только учеба, но и участие в масштабных форумах, проводимых как в вузах, так и в республике в целом. Примером может служить круглый стол «Народы Мордовии в годы Великой Отечественной войны. 1941-1945 гг.», имевший своей целью воспитание патриотизма и гражданской ответственности. Привлечение иностранных студентов к подобным мероприятиям позволяет воспитывать культуру межнационального общения среди обучающихся. Работа в данном направлении ведется очень активно. В рамках фестиваля культур «Огарёвский колорит», приуроченного к Международному дню студентов, в Мордовском университете в 2020 году состоялся круглый стол «Великая Победа в судьбах государств». Наряду с преподавателями и студентами из России, с большим интересом в обсуждении участвовали иностранные студенты». На связь с огарёвцами вышли активисты из Сербии, волонтеры Победы из Эстонии, аспиранты из Мексики и Эквадора, координатор Бессмертного полка из Италии. Все они занимаются изучением Великой Отечественной войны, а также восстановлением памятников и добровольчеством.

Как уже было сказано, многие иностранные студенты выделяют в качестве фактора, затрудняющего процесс адаптации, невладение русским языком. В этом направлении учебными учреждениями ведется большая работа. Так, каждый год среди иностранных студентов проводится викторина на знание русского языка и литературы «Глаголом жечь сердца людей...». Викторина играет очень большую роль в преодолении языковой и культурной изоляции иностранных обучающихся, включении их в процесс студенческой коммуникации. Таким образом осуществляется интеграция обучающихся иностранцев со студентами, проживающими на территории Республики Мордовия.

Анализ плана мероприятий, проводимых с иностранными студентами в МГУ им. Н.П. Огарёва, позволяет увидеть, что большое значение в их адаптации отводится национальным праздникам. Студентам-мигрантам предоставляется возможность отпраздновать, например, такие праздники, как «Навруз», «Холи» и другие. Как уже было сказано, в университете работает Управление международных связей, в которое иностранный студент может обратиться абсолютно по любому вопросу. Под руководством данного структурного подразделения иностранные студенты проводят Международный фестиваль «Мы разные, но мы вместе», который, как правило, приурочен к международному дню студента. К этому культурному мероприятию студенты готовят различные художественные номера, отражающие их национальный колорит. Самые лучшие из них принимают участие в Международном региональном фестивале национальных культур иностранных студентов «Все флаги в гости к нам». На протяжении трех последних лет студенты из Мордовского университета занимают на Фестивале первые призовые места (Студенты-мусульмане превосходно вписываются в светскую жизнь Мордовии).

Отметим, что участие учебных учреждений в международном образовательном процессе повышает их статус на рынке образовательных услуг, поэтому ВУЗы за- 
интересованы ежегодно привлекать как можно больше иностранных студентов. Для этого они ведут активную работу по совершенствованию адаптационной деятельности, по скорейшей интеграции иностранных студентов в новое для них социокультурное пространство, все это влечет за собой улучшение качества их учебы и досуга, а в долгосрочной перспективе повышает вероятность того, чтобы для большей части иностранных студентов Россия и Мордовия стали второй родиной.

\section{Источники и материалы}

Миграция населения Республики Мордовия за 2019 год: Статистический сборник № 903 // Территориальный орган Федеральной службы государственной статистики по Республике Мордовия, 2020. http:// mrd.gks.ru.

Международные связи // Мордовский государственный университет имени Н.П. Огарева. https://www.mrsu.ru/ru/international/

Студенты-мусульмане превосходно вписываются в светскую жизнь Мордовии. https://smnews.ru/studenty-musulmane-prevosxodno-vpisyvayutsya-v-svetskuyu-zhizn-mordovii-5190/.

Территориальный орган УФМС России по Республике Мордовия: Официальный сайт. http:// fmsrm.ru.

Территориальный орган Федеральной службы государственной статистики по Республике Мордовия, 2020. http:// mrd.gks.ru.

\section{Научная литература}

Воробьева И.М. Иностранные студенты в российском вузе // Молодой ученый, 2015. № 10. C. $1115-1119$.

Гез Т.А., Старикова В.О. Иностранные студенты, мигрирующие в Россию: проблемы адаптации и способы их решения // Информация-Коммуникация-Общество, 2018. Т. 1. С. 88-94.

Грибанова В.В., Жерлицына Н.А. Африканцы в вузах России: особенности социокультурного взаимодействия // Россия и Африка: проблемы национально-государственной идентичности. Москва, Федеральное государственное бюджетное учреждение Институт Африки PAH, 2012. C. 63-79.

Зангиева И.К., Сулейманова А.Н. Студенты из стран СНГ в России: предпосылки к миграции // Мониторинг общественного мнения, 2016. № 5. С. 127-146.

Никонова Л.И. Адаптация и интеграция мигрантов: этнокультурный, социальный, региональный аспекты. Вопросы и анкеты для историко-этнографического исследования / Л.И. Никонова, А.И. Минакова; НИИ гуманитарных наук при Правительстве Республики Мордовия. Москва, 2020. 48 с.

Отставнова И.В. Пространство Российской провинции «жизнесмыслы». Автореф. на соиск. учен степ. кандидата культурологи. Саранск: Морд. гос. ун-т им. Н.П. Огарёва. 2006. 17 с.

Серафимович A.Е. Образовательная миграция и обучение иностранных студентов: современное состояние, тенденции развития // Юридическое образование и наука, 2018. № 1. С. 19-23.

Akhanteva, Natalia V. and Nazirjon N. Abduganiev

\section{Adaptation of the Migrant Students to the New Sociocultural Context in the Universities of Mordovia}

DOI: $10.33876 / 2311-0546 / 2021-54-2 / 241-247$

Educational migration plays an important role in the structure of all migrations into Russia. Every year a large number of young people come to our country in order to get an education, and many of them plan to stay in the Russian Federation for permanent residence. At first 
many migrant students experience inconvenience due to the language barrier, the new socio-cultural context and unfamiliar climatic conditions. The universities of the Russian Federation, in particular the universities of the Republic of Mordovia, face the challenge of creating favorable conditions for the fastest possible adaptation of foreign students. Ethnographers can also contribute to resolving the problem, and it is reflected in various scientific studies. The article attempts to analyze the efforts of the two largest universities of the republic to provide migrant-friendly environment for the foreign students. These educational institutions have been working in this direction for more than a dozen years, each year making more progress in accordance with the realities of the modern world.

Keywords: socio-cultural context, student migration, migrant students, foreign students, ethnocultural adaptation

For Citation: Akhanteva, N.V., and N.N. Abduganiev. 2021. Adaptation of the migrant students to a new sociocultural context in the Universities of Mordovia. Herald of Anthropology (Vestnik Antropologii) 2: 241-247.

\section{Author Info:}

Akhanteva, Natalia V. - lecturer, Ogarev Mordovia State University (Saransk, Russian Federation).E-mail: akhanteva.natasha@mail.ru

Abduganiev, Nazirjon N. - Deputy Chairmen of the Board, Assembly of the Peoples of Russia (Moscow, Russian Federation).E-mail: nazir1970@yandex.ru

\section{References}

Gez, T.A., and V.O. Starikova, 2018. Inostrannye studenty, migriruyushchie v Rossiyu: problemy adaptatsii i sposoby ikh resheniya [Foreign students migrating to Russia: problems of adaptation and ways to solve them]. Informatsiya-Kommunikatsiya-Obshchestvo 1: 88-94.

Gribanova V.V., and N.A. Zherlitsyna. 2012. Afrikantsy v vuzakh Rossii: osobennosti sotsiokul'turnogo vzaimodeistviya [Africans in Russian universities: features of sociocultural interaction]. In Rossiya i Afrika: problemy natsional'no-gosudarstvennoi identichnosti [Russia and Africa: problems of national-state identity]. Moscow: Federal'noe gosudarstvennoe byudzhetnoe uchrezhdenie Institut Afriki RAN.

Nikonova, L.I., Minakova, A.I. 2020. Adaptatsiya i integratsiya migrantov: etnokul'turnyi, sotsial'nyi, regional 'nyi aspekty. Voprosy i ankety dlya istoriko-etnograficheskogo issledovaniya [Adaptation and integration of migrants: ethnocultural, social, regional aspects. Questions and questionnaires for historical and ethnographic research]. Moscow, NII gumanitarnykh nauk pri Pravitel'stve Respubliki Mordoviya.

Otstavnova, I.V. 2006. Prostranstvo Rossiiskoi provintsii «zhiznesmysly» [The space of the Russian province "zhiznyhmysly"]. Abstract of PhD thesis. Saransk.

Serafimovich, A. E. 2018. Obrazovatel'naya migratsiya i obuchenie inostrannykh studentov: sovremennoe sostoyanie, tendentsii razvitiya [Educational migration and training of foreign students: current state, development trends]. Yuridicheskoe obrazovanie i nauka 1: 19-23.

Vorobieva, I.M. 2015. Inostrannye studenty v rossiiskom vuze [Foreign students in a Russian university]. Molodoi uchenyi 10: 1115-1119.

Zangieva, I. K., Suleimanova, A.N. 2016. Studenty iz stran SNG v Rossii: predposylki k migratsii [Students from CIS countries in Russia: preconditions for migration]. Monitoring obshchestvennogo mneniya 5: 127-146. 